\title{
ガスクロマトクラフィーによる局所麻酔剤の分析
}

\author{
浜田昭, 武田 靖子, 郷右近 菊子 \\ 昭和大学薬学部1)
}

\section{Analysis of Local Anesthetics by Gas-liquid Chromatography}

\author{
Akira Hamada, Yasuko Takeda and Kikuko Goukon \\ School of Pharmaceutical Sciences, Showa University ${ }^{1)}$
}

(Received August 16, 1968)

\begin{abstract}
Gas-liquid chromatography of 10 kinds of local anesthetics has been carried out on $1 \mathrm{~m}$ column packed with Daichrom A (washed Celite 545) coated with $1 \%$ silicone QF-1 or with Daichrom F (quartz powder) coated with $0.5 \%$ thermol No.3. Each sample (in free base state) in ethanolic solution was introduced into gas chromatograph equipped with hydrogen flame ionization detector. The column with thermol No. 3 was preferred for the separation of all these drugs including dibucaine which had been difficult to detect with gas-liquid chromatography.

Rapid and superior separation of a mixture of these drugs was also performed by thermol No. 3 column using a temperature gradient.
\end{abstract}

臨床各科の手術などの際に，局所森酥剤を使用して， いわゆるショック死などの事故を起こすことは，最近で も依然としてあとを絶たない状態である.22これら事故 の場合, 裁判化学的には注射部位, 血液, 脳春䯣液, 委 たは施用した薬剤の残部といったものから使用した微量 の局所麻酔剤の检出を行なら必要が㘯る。

著者の一人はささにガスクロマトグラフィーによる各 種局所麻酸剤の分析法について検討し，この方法が微量 の局所麻䣲剤の定性試験に有用な分析法であることを報 告した.33

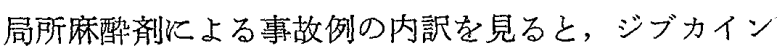
によるものが压倒的に多く，大半をしめている.2,4) しか 乙前報の結果では, ジブカインは強い条件によってのみ クロマトグラム上にピークを与えたが，まだ十分満足す べきものではなかった，局所麻醉剤の分析法についての
報告は多いが，㐏の大部分は沈股反応，呈色反応，紫外 線 (UV) 打よび赤外線 (IR) 吸収, ペーパークロマト グラフィーや薄層クロマトグラフィーによるものが多く ガスクロマトグラフィーによる局所麻㜞剤の分析例は比 較的少なく,5) しかもジブカインについての報告は他に 見られない。

本報で注ジブカインについて特に検討し，また10種の 局所麻醉剂についての一齐分析を試み, さらに昇温ガス クロマトグラフィーに上る分析を検討し，好結果が得ら れたので報告する。

\section{実 験 方 法}

1. 試料および試験溶液の調製 陚料として用いた局 所麻酔剂は Table I V揭げる10種のもので，いずれも 市販品を用いた。各軾料は塩を形成しているものはとの 水溶液（製剤化してあるるのは直接）を10\%水酸化ナト

1）Location: Hatanodai-1, Shinagawa-ku, Tokyo (東京都品川区旗の台 1-5-8).

2）“楽物汇上る中毒事故等の発生状況，1957-1966年，”科学整察研究所資料，1958-1967.

3）浜田 昭, 星野乙松, 丹沢珪子, 浮田忠之進, 衛生化学, 10, 14 (1964).

4）丹沢珄子, 星野乙松, 浮田忠之進, 衛生化学, 12, 129 (1966).

5） a) 宮下 繁, 松村芳子, 科学警察研究所報告, 16, 295 (1963)；b) H. M. Koehler, J. J. Hefferren, J. Pharm. Sci., 53, 745 (1964). 
リウム溶液で, アルカリ性としたのち、エーテルで抽出 する. 土一テル層浐乾燥後エーテルを留去し，遊離型と なっている残留物を $1 \%$ 江冺溶液として試験溶液 とした。

\section{Gas Chromatography Hitachi Gas Chromato-} graph model $\mathrm{K}-53$ equipped with hydorogen flame ionization detector and an automatic temperature programmer

column : $100 \mathrm{~cm}$ stainless steel, i. d. $3 \mathrm{~mm}$

(1) $1 \%$ Silicone $\mathrm{QF}-1$ on Daichrom A (60-80mesh) ${ }^{6)}$

(2) $0.5 \%$ Thermol No. 3 on Daichrom F (60-80 mesh) ${ }^{63}$

Carrier gas : $\mathrm{N}_{2}$

Table I. Local Anesthetics Tested

$\begin{array}{ll}\text { 1. Benzoic acid ester } & \text { 3. Anilide derivative } \\ \text { Hexylcaine(Hex) } & \text { Lidocaine(Lid) } \\ \text { 2. Amino-benzoic acid ester } & \text { Carbocaine(Car) } \\ \text { Anesthesin(Ane) } & \text { 4. Quinoline derivative } \\ \text { Procaine(Pro) } & \text { Dibucaine(Dib) } \\ \text { Cornecain(Cor) } & \text { 5. Cocaine derivative } \\ \text { Tetracaine(Tet) } & \text { Cocaine(Coc) } \\ \text { T-cain } & \end{array}$

結果および考察

Table I に示した各局所麻酔剂を用いてガスクロマト グラフィーを行なった場合の条件祘よび得られた保持時 間を Table II， IIIに示した。

QF-1 のカラムでは幾分吸着現象汃見られ，之くに保 持時間の長いもの (Dib)については，注入サンプル量に よってピークの最大值の移動が見られる。しかし過剩の サンプル添加を避忛，感度を上げて行なうと良いピーク を得ることが出来る.カラム温度を上昇し，240Kすれば この様な現象は見られなくなり，保持時間の再現性も良 くなる。しかしながら保持時間の短かいものについては

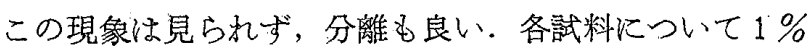
溶液 $1 \mu \mathrm{I}$ を用いたときの保持時間を Table II に示した. ただし Cor については前回報告したごとく，またつぎ に述べる thermol No.3 カラムのときと同様に他のもの とくらべ非常に感度が低く，1 $1 \mu 1$ (Cor として $10 \mu \mathrm{g}$ )の サンプル量ではピークが得られず，サンプル量を非常に 增加し，10 $\mathrm{ml}(100 \mu \mathrm{g})$ を用い，2200の条件ではじめて ピークが得られた。

Koehler $^{5 b)}$ 等(固定相液体にSE-30を用い，種々の担 体を検討した結然，glass bead が最も良い結舀を与えた ことを報告している．前国比較的好結果を示した ther-
Table II. Retention Time of Local Anesthetics by Silicone $Q F-1$ Column (in minutes) ${ }^{a}$

\begin{tabular}{lccc}
\hline $\begin{array}{l}\text { Condition } \\
\text { Column temp. } \\
\text { Flow rate }\end{array}$ & $\begin{array}{c}150^{\circ} \\
20 \mathrm{ml} / \mathrm{min}\end{array}$ & $\begin{array}{c}200^{\circ} \\
40 \mathrm{ml} / \mathrm{min}\end{array}$ & $\begin{array}{c}220^{\circ} \\
20 \mathrm{ml} / \mathrm{min}\end{array}$ \\
\hline $\begin{array}{l}\text { Anesthesin } \\
\text { Hexylcaine }\end{array}$ & 1.1 & 0.3 & \\
Procaine & 7.1 & 0.6 & \\
Lidocaine & 7.6 & 1.1 & 0.8 \\
Cocaine & & 1.2 & \\
Carbocaine & & 1.8 & \\
Tetracaine & 14.3 & 2.0 & 1.3 \\
T-cain & & 2.7 & \\
Cornecain & & $\mathrm{n.r}$. & $3.5 \mathrm{c}$ \\
Dibucaine & & 9.9 & \\
\end{tabular}

a) The retention time was measured from the appearance of solvent (ethyl alcohol).

b) $1 \% \mathrm{QF}-1$ on $60-80$ mesh Daichrom $\mathrm{A}$, injection port temp.: $250^{\circ}$, attenuation: $\times 100$, sample size: $1 \mu 1$ of each $1 \%$ solution

c) sample size: $10 \mu 1$ of $1 \%$ sample solution

n.r.: no response observed

TABLE III. Retention Time of Local Anesthetics by Thermol No. 3 Column (in minutes) ${ }^{a}$

\begin{tabular}{lcccc}
\hline $\begin{array}{l}\text { Condition } \\
\text { Column temp }\end{array}$ & $80^{\circ}$ & $200^{\circ}$ & $230^{\circ}$ & $\begin{array}{c}\text { Limit } \\
\text { of } \\
\text { detection } \\
(\mu \mathrm{g})\end{array}$ \\
\hline Anesthesin & 0.8 & 0.4 & & \\
Hexylcaine & 3.6 & 1.5 & & \\
Procaine & 4.7 & 1.8 & & 0.002 \\
Lidocaine & 2.7 & 1.2 & & \\
Cocaine & 8.5 & 3.2 & & \\
Carbocaine & 5.4 & 2.1 & & \\
Tetracaine & 10.2 & 3.7 & & \\
T-cain & 17.6 & 6.1 & 2.1 & 0.1 \\
Cornecain & $\mathrm{n} . \mathrm{m}$. & $7.4^{\circ)}$ & & \\
Dibucaine & 57 & 18.0 & 5.7 & 0.3 \\
\hline
\end{tabular}

a) The retention time was measured from the appeara. nce of solvent (ethyl alcohol)

b) $1 \%$ thermol No. 3 on $60-80$ mesh daichrom $F$, injection port temp.: $250^{\circ}$, attenuation: $\times 100$, sample size: $1 \mu l$ of each $1 \%$ solution

c) condition tested: procaine (conc. of sample solution, $0.0001 \%$; column temp., $180^{\circ}$; flow rate, $40 \mathrm{ml} / \mathrm{min}$; attenuation, $\times 10)$, T-cain $\left(0.01 \% ; 230^{\circ} ; 40 \mathrm{ml} / \mathrm{min}\right.$; $\times 20)$, Dibucaine $\left(0.01 \% ; 200^{\circ} ; 40 \mathrm{ml} / \mathrm{min} ; \times 20\right)$

d) sample size $6 \mu \mathrm{l}$ of $1 \%$ sample solution n.r.: no response observed

mol-Q カラムが市肘品で，その組成も明らかでなく，一 般的でないので, 今回は液相として高沸点用の thermol

6) 大倉理化学研究所製：Daichrom A (washed Celite 545), Daichrom F (quartz powder). 
No，3を用小，担体として出来るだけ吸着の少ないとい るれている水晶粉末を用いてガスクロマトグラフィーを 試みた.

この thermol No. 3 のカラムは今迄検討を加光た力 ラムの中では最方優れ; 分離能も高く,再現性も良い，特 に従来良いピークを得られなかったDibが比較的㸚称的 な型のピークを与光，しかも緩和な温度条件で感度もよ く分析することが出来る。

従来の報告を見ると Dib や Corを除いた比較的がス クロマトグラフィーによって分析されやすい局所麻酔剤 に挌いても，大抵の場合 $210^{\circ}$ 以上のカラム温度に和いて

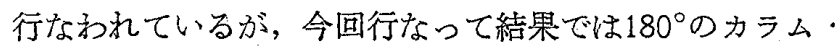
温度で主な局所麻酔剤は，短時間で溶出され，200でい Dibを除いては10分以内にク口マトグラム上，それぞれ 良いピークを示し，同定することが出来る. Cor 怯この カラムの場合では QF-1 カラムに比較すると多少感度が あがっているが，やはり多量のサンプル量を必要とす る.7) Table III K各試験溶液 $1 \mu \mathrm{l}(10 \mu \mathrm{g})$ (Cor Kつw ては $60 \mu \mathrm{g}$ ) を用いたとさの保持時間を示した。をた主 な局所麻酔剤の榆出限度を最右櫚に示した。

ここに用いた局所麻酔剤は十分再現性よくこのカラム によって分離することが示されたが，QF-1 カラムに比 ベるとLidがHexやProより早く溶出され，またCarと Coc の溶出順序の逆転が認められる.

また局所麻酔剤混合物の分析を行ならために各局所麻

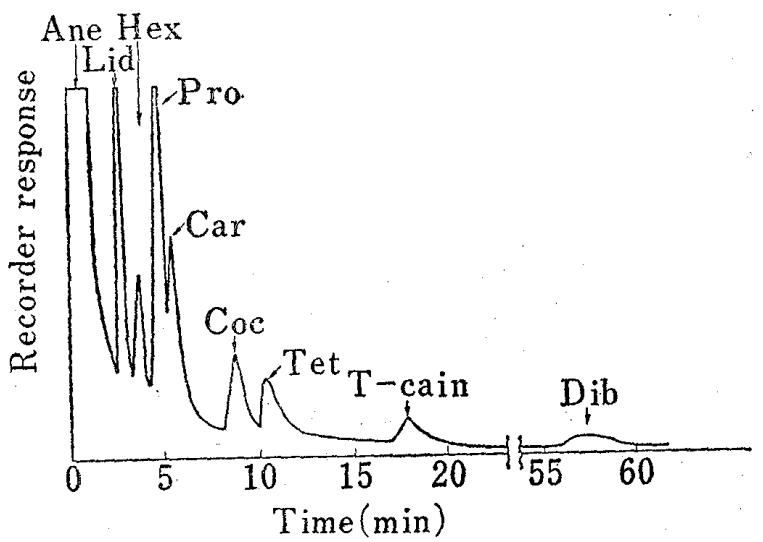

Fig. 1. Chromatogram of $10 \mathrm{Local}$ Anesthetics condition; column: $100 \times 0.3 \mathrm{~cm}$ i.d. stainless steel, $0.5 \%$ thermol No. 3 on Daichrom F (60-80 mesh), flow rate: $30 \mathrm{ml} / \mathrm{min} \mathrm{N}_{2}$, column temp.: $180^{\circ}$, injection port temp. $250^{\circ}$, sensitivity (attenuation): $\times 100$. sample size: $10 \mu 1$ of a mixture $(10 \mathrm{ml})$ prepared from each $1 \mathrm{ml}$ of $1 \%$ ethanolic solution
酔剂の $1 \%$ 溶液を等量混合して，その $10 \mu \mathrm{l}$ (各試料につ いて $10 \mu \mathrm{g})$ を用い, thermol No.3カラムにより，180 の条件下で行なったときのクロマトグラムをFig. 1 に示 した. Fig.1から明らかなごとく， Cor はこの量ではピ 一クを与えていないし，Dibにはこの温度条件は低過ぎ て良い条件とはいえないが，その他のものについては非 常に良く分離し，同定が可能である．ここに用いた試料 溶液は各試料の濃度が 0.1\%で，したがって注入した溶 媒の量が多過ぎたため，Aneは溶媒として用いたェタノ ールのピークにかくれてしまっている。

局所柇酔剂は乞の種類も多く，また化学的組成も種々 であり，同一条件で一斉に分析を行なうことはかなり困 難とされて和り，乙たがって局所麻酔剤の種類によって 色々と条件を変えて行なう必要があった，上にのべたご とく，今回用いた Table III に示したような条件で行な らときここで用いた試料について同一条件で分離，同 定することが可能である（例Fig. 1) が，さらに昇温が スクロマトグラフィーによる局所麻酔剂の混合物の分離 を試みた，試験溶液としてCorを3\%，Dibを $2 \%$ ，を の他のものは1\%に含まれるように調製した混合物のア ルコール溶液 $1 \mu \mathrm{l}$ を用い, thermol No. 3 カラム, カラム 温度: 最初 $150^{\circ}$, 最終 $220^{\circ}$, 开温速度 $5^{\circ} / \mathrm{min}$ の条件で 行なった。得られたクロマトグラムはFig. 2 に示してあ

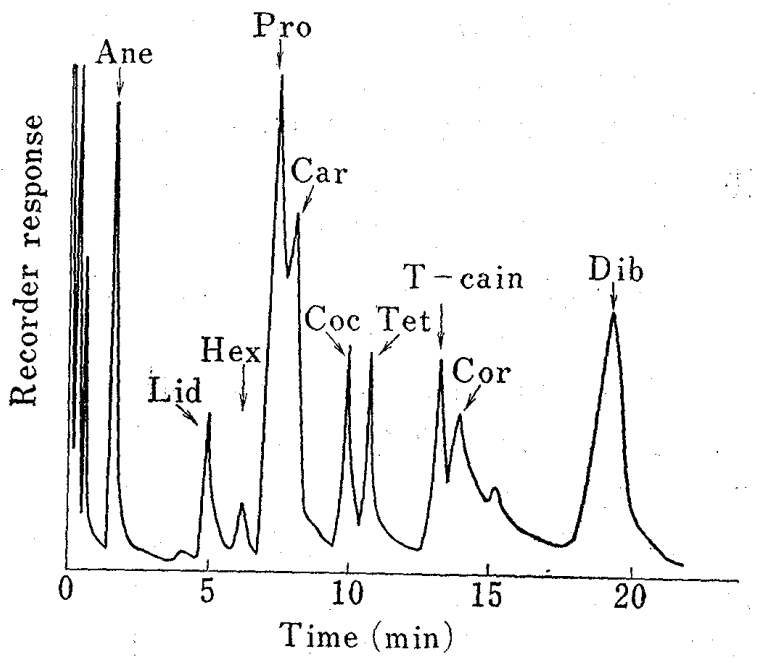

Fig. 2. Separation of 10 Local Anesthetics under Temperature Gradient Condition

condition; column: same as given in Fig, 1, flow rate: $40 \mathrm{ml} / \mathrm{min} \mathrm{N}_{2}$, column temp.: initial temp. $150^{\circ}$ with temp. increase of $5^{\circ} / \mathrm{min}$, final temp. $220^{\circ}$, injection port temp. $250^{\circ}$, sensitivity (attenuation): $\times 200$ sample size: $1 \mu \mathrm{l}$ of an alcoholic solution containing dibucaine $(2 \%)$, cornecain $(3 \%)$ and others $(1 \%)$

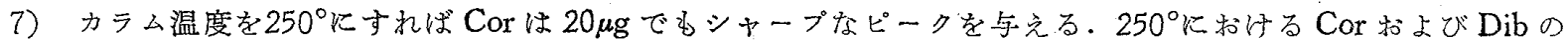
保持時間はそれぞれ $1.5,2.7 \mathrm{~min}$ である。 
るが，用いた局所麻酔剂はそれぞれよく分離し，本昇温 ガスクロマトグラフィーによる法は一斉分析の方法とし て非常によいことが分った。

以上述べた結果から明らかなように, 従来ガスクロマ トグラフィーによって良い結果が得られていなかったジ ブカインが，今回用いた thermol No.3カラムによって 感度よく，乙かる対称的なピークとして検出された。 たこのカラムによって局所麻酶剤の同一条件下に拈ける

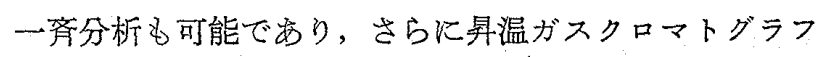

イーを行なえば、より容易に定性試験を行なえるばかり でなく，正確かつ迅速に，乙か子微量分析が可能である. 今回試験した QF-1 カラム拉よび thermol No.3 カラ ムによるDibの溶出パターンの相異は，固定相に用いた 担体による差が大い影響していると思秃る。この点 そついてはさらに検討を加党ている。

謝辞 サンプルの一部を提供していただいた東京大学 薬学部薬害研究施設大沢利昭助教授に感謝する。 